\title{
Peripheral Blood Catalase in Patients Undergoing Renal Transplantation
}

\author{
Lawrence Rosenberg, M.D., Ph.D., ${ }^{\prime}$ Robert M. Merion, M.D., \\ Darrell A. Campbell, JR,, M.D., Donald C. Dafoe, M.D., Susan Clarke, B.S., \\ LESLIE Rocher, M.D., AND JeREMiah G. TuRCotTE, M.D. \\ University of Michigan Organ Transplantation Center and Department of Internal Medicine, Division of \\ Nephrology, University of Michigan Medical Center, Ann Arbor, Michigan 48109-0331
}

Presented at the Annual Meeting of the Association for Academic Surgery, Orlando, Florida, November 1-4, 1987

\begin{abstract}
Oxygen frec radicals arc mediators of tissuc injury and catalasc is an enzyme which is involved in limiting this process. We examined peripheral blood catalase activity (PBCA) to assess its value as a marker in detecting tissue injury related to renal allograft rejection. Thirty-one consecutive recipients of kidney $(n=29)$ or simultaneous kidney/pancreas $(n-2)$ transplants and 10 normal volunteers were studied. Catalase activity, measured by the disk-flotation method, was expressed as Sigma units $\times 10^{-3} / \mathrm{ml}(\mathrm{SU} / \mathrm{ml})$ of whole blood. Normal PBCA was determined to be greater than $76 \mathrm{SU} / \mathrm{ml}$. Twenty-nine episodes of renal allograft rejection (diagnosed by clinical criteria \pm biopsy [79\%]) were observed in 26 patients. PBCA (mean \pm SEM) was found to be low $(64 \pm 1 \mathrm{SU} / \mathrm{ml})$ in $28 / 29$ episodes $\left(\chi^{2}=46.3, P<0.001\right)$, and the decrease (at least two consecutive daily catalase values $<76 \mathrm{SU} / \mathrm{ml}$ ) occurred 2 days prior to the clinical/biopsy diagnosis of rejection in $26 / 28$ episodes. The sensitivity of PBCA as a discriminant of rejection was $97 \%$, specificity was $96 \%$, and test accuracy was $96 \%$. PBCA less than $50 \mathrm{SU} / \mathrm{ml}$ on two or more occasions occurred in five cases and transplant nephrectomy was required in four of these because of uncontrollable rejection. Nine episodes of cyclosporine nephrotoxicity occurred in 7 patients and none of these episodes was associated with a decreased PBCA. Our data suggest that decreased PBCA is a sensitive and specific indicator of renal allograft rejection. PBCA remains normal during episodes of cyclosporine nephrotoxicity and therefore provides a rapid and inexpensive discriminant from allograft rejection. (c) 1988 Academic Press, Inc.
\end{abstract}

\section{INTRODUCTION}

The molecular mechanisms responsible for allograft destruction are not well defined. One possible mechanism involves the participation of cells, such as polymorphonuclear leukocytes, macrophages, and monocytes, which are able to undergo a "respiratory burst" $[1,2]$ and subsequently generate toxic oxygen free radicals $[1,5,6]$. These substances result in peroxidative damage to the lipid bilayer of cell membranes and ultimately cause cell death.

Normal tissues contain enough endogenous scavengers to protect against oxygen free radical damage. Such defense systems, however, may be affected by the ongoing rejection and destruction of a transplanted graft [7]. In this regard, the activity of the primary antioxidant defense enzyme super-

\footnotetext{
' Supported by the McLauglin Foundation of Canada.
}

oxide dismutase has been found to be decreased in rejecting rat cardiac allografts [7].

Catalase, the first enzyme ever described [8], is an antioxidant enzyme whose primary function is to metabolize hydrogen peroxide $\left(\mathrm{H}_{2} \mathrm{O}_{2}\right)$ to $\mathrm{H}_{2} \mathrm{O}$ and $\mathrm{O}_{2}[8,9]$. Catalase activity in urine and blood has been studied in a variety of disease states $[8,10,11]$, including acute and chronic renal failure [12], and has always been found to be elevated. The hypercatalasemia of uremia is reduced by dialysis and in the early post-transplant period [12].

The purpose of our investigation was to study peripheral blood catalase activity to assess its value as a marker of renal allograft rejection.

\section{MATERIALS AND METHODS}

\section{Patients}

A study of consecutive cadaver-donor ( $n$ $=21)$ and living-related-donor $(n=10)$ renal 
transplant recipients (13 females; 18 males) with a mean age of 33 years (range 9-57 years) was carried out. Twenty-eight patients received a primary renal graft. One patient received a second renal allograft and two underwent simultaneous kidney/pancreas transplantation. Renal recipients were immunosuppressed with prednisone $(1.5 \mathrm{mg} / \mathrm{kg}$ in preop and then tapered to $0.25 \mathrm{mg} / \mathrm{kg}$ po over 4 weeks) and cyclosporine $(5 \mathrm{mg} / \mathrm{kg}$ iv and then $16 \mathrm{mg} / \mathrm{kg}$ po to maintain a blood level of $150-250 \mathrm{ng} / \mathrm{ml}$ by HPLC). One recipient of an HLA-identical living-related kidney received prednisone and azathioprine ( $3 \mathrm{mg} / \mathrm{kg}$ po preoperatively and $3 \mathrm{mg} / \mathrm{kg}$ po/iv daily up to a maximum of $200 \mathrm{mg} /$ day). Recipients of combined renal/pancreas transplants received quadruple immunotherapy with prednisone and cyclosporine as for renal transplants, azathioprine (1.5-2.5 $\mathrm{mg} / \mathrm{kg}$ po/iv daily up to a maximum of 200 $\mathrm{mg} /$ day), and Minnesota antilymphoblast globulin $(20 \mathrm{mg} / \mathrm{kg}$ iv for 10 days). All patients were studied until discharge from hospital and then weekly in the outpatient clinic. Median time of follow-up was 6 wecks.

\section{Diagnosis of Rejection}

The diagnosis of graft rejection was established by an independent observer on the basis of at least three of the following clinical criteria as suggested by McWhinnie et al. [4].

(1) Graft tenderness \pm swelling.

(2) Fever (in the absence of infection).

(3) Oliguria (in the absence of urinary obstruction) or a decreasing urine output of approximately $10 \%$ /day on the 2 preceding days.

(4) A rising creatinine of approximately $10 \% /$ day on the 2 preceding days.

(5) Response to a series of methylprednisolone pulses.

In addition, confirmatory percutaneous biopsies were obtained in $79 \%$ of rejection episodes. Twenty-nine rejection episodes were diagnosed in 26 patients.

\section{Diagnosis of Cyclosporine Nephrotoxicity}

Cyclosporine nephrotoxicity was diagnosed if abnormal renal function improved following a reduction in cyclosporine dosage. In each instance, the cyclosporine blood level was greater than $250 \mathrm{ng} / \mathrm{ml}$ and there was no clinical/biopsy evidence of rejection, obstruction, or infection.

\section{Determination of Peripheral Whole Blood Catalase (PBCA)}

PBCA was analyzed using the disk-flotation technique described by Gagnon $e t$ al. [13] and Charbonneau et al. [14] which takes advantage of the specific ability of catalase to cleave $\mathrm{H}_{2} \mathrm{O}_{2}$ into $\mathrm{H}_{2} \mathrm{O}$ and $\mathrm{O}_{2}$. As the reaction proceeds, bubbles of oxygen are liberated and cause the disk to float to the surface. Disk-flotation time (in seconds) is inversely related to catalase activity.

\section{Procedure}

(1) Heparinized blood samples $(5-10 \mathrm{ml})$ were collected daily and refrigerated at $10^{\circ} \mathrm{C}$. Samples were brought to room temperature prior to PBCA determination.

(2) Blood samples were diluted 1:1000 with $0.9 \%$ saline solution in a glass tube.

(3) Using fine forceps, a filter paper disk (Whatman, quality No. 1) of uniform diameter $(7 \mathrm{~mm}$, standardized using a hole punch) was placed for $3 \mathrm{sec}$ into the glass tube containing the solution of diluted blood.

(4) The saturated disk was gently transferred to a second glass tube containing $8 \mathrm{ml}$ of $3 \% \mathrm{H}_{2} \mathrm{O}_{2}$ (Medikay). When the disk settled at the bottom, a digital timer was started. When the disk reached the top of the column of hydrogen peroxide, the timer was stopped.

(5) Samples were run in triplicate and the results were averaged. Interassay and intraassay variabilities were less than $10 \%$. 
Development of a Standard Curve of Catalase Activity

Catalase was purchased from Sigma Chemical Co., St. Louis, Missouri (Catalog No. C100) with a specific activity of 44,200 Sigma units (SU) per milligram. One SU of catalase activity is defined as that amount of enzyme which decompose $1.0 \mu M$ of $\mathrm{H}_{2} \mathrm{O}_{2}$ in $1 \mathrm{~min}$ at $\mathrm{pH} 7.0$ at $25^{\circ} \mathrm{C}$.

Disk-flotation times were determined for catalase samples of known activity. A logarithmic regression was performed by a leastsquares method using a commercial software package and microcomputer (Fig. 1). The correlation coefficient for the regression equation was 0.96 . Results were expressed as catalase activity $\left(\mathrm{SU} \times 10^{-3}\right)$ per milliliter whole blood.

\section{Establishment of Normal PBCA Using the Disk-Flotation Method}

Samples were obtained from 10 healthy age-matched volunteers for determination of $\mathrm{PBCA}$. PBCA (mean $\pm \mathrm{SD}$ ) for these individuals was $96 \pm 10 \mathrm{SU} / \mathrm{ml}$. The $95 \%$ confidence level for the lower limit of PBCA in healthy individuals was $76 \mathrm{SU} / \mathrm{ml}$. PBCA less than $76 / \mathrm{SU} / \mathrm{ml}$ on 2 consecutive days was considered to be abnormal.

\section{Mixing Studies}

To determine whether a low PBCA in patients undergoing rejection was due to the presence of a blocking factor as opposed to

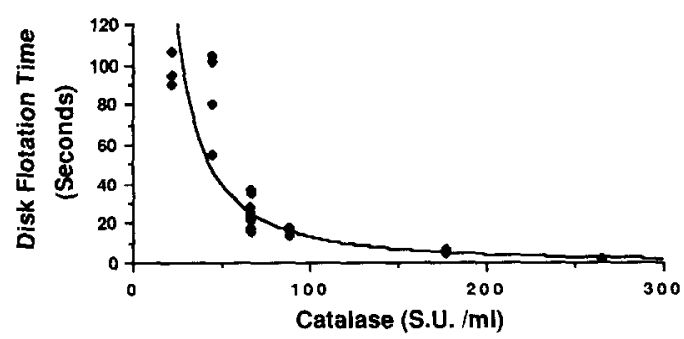

FIG. 1. Standard curve for peripheral blood catalase activity by disk-flotation method. Logarithmic regression by least-squares method, $Y=(1.997)\left(10^{4}\right)$ $\left(X^{-1.5917}\right), R=0.96$.
TABLE 1

Peripheral Blood Catalase Activity in Renal. AII OGRAFT RFCIPIENTS

\begin{tabular}{lcc}
\hline Catalase & Rejection $(n)$ & No rejection $(n)^{a}$ \\
\hline$<76 \mathrm{SU} / \mathrm{ml}$ & 28 & 1 \\
$>76 \mathrm{SU} / \mathrm{ml}$ & 1 & 24 \\
\hline
\end{tabular}

Note. Sensitivity $=97 \%$, specificity $=96 \%$, accuracy $=96 \%$.

${ }^{a}$ No rejection episodes, $n=6$; following recovery from a rejection episode, $n=19$.

an actual decrease in the amount of enzyme, blood from a patient with documented rejection and low PBCA was diluted 1:1000 with 0.9 saline as per our protocol. Aliquots were then mixed, in dilutions of $1: 4,1: 2$, and $1: 1$ (rejecting:normal), with samples of saline-diluted blood taken from a normal volunteer. PBCA was then determined on the mixed specimen.

\section{Statistical Analysis}

Comparisons of frequency were performed by $\chi^{2}$ analysis. Comparisons of means were performed by the nonparametric Wilcoxon rank sum test or signed rank test, where appropriate. $P<0.01$ was considered significant.

\section{RESULTS}

Allograft rejection was associated with significantly decreased PBCA. As shown in Table 1, decreased PBCA was observed in 28 of 29 rejection episodes (sensitivity $=97 \%$ ). Conversely, normal PBCA was seen in five of six rejection-free patients and in all patients $(n=19)$ who recovered from a rejection episode $($ specificity $=96 \%)$. PBCA results, therefore, had an overall accuracy of $96 \%$ in diagnosing the presence or absence of rejection $\left(\chi^{2}=46.3 ; P<0.001\right)$.

One false positive result occurred in a pediatric recipient who has never had a clinical or biopsy diagnosis of rejection. This patient has had no infections or other complications during the 8 months post-transplant. The 
only false negative occurred in a recipient of an HLA-identical living-related kidney. On the fifth post-transplant day, the serum creatinine level rose from 1.4 to $2.5 \mathrm{mg} / \mathrm{dl}$ and low grade fever, hypertension, decreased urine output, and slight graft tenderness were noted. Whole blood cyclosporine trough levels remained in the therapeutic range during this interval and a response to intravenous methylprednisolone was noted over the following 3 days.

Aside from the single example of a false negative, decreased PBCA was noted at least $48 \mathrm{hr}$ prior to the clinical and/or biopsy diagnosis of allograft rejection in every case. In 26 or 28 rejection episodes, decreased PBCA occurred 2 days prior to the diagnosis of rejection and catalase criteria were met 5 and 7 days prior to the diagnosis in the remaining two cases.

Mean PBCA 48 hr prior to the clinical declaration of rejection was $64 \pm 1 \mathrm{SU} / \mathrm{ml}$. PBCA in $(n=22)$ recipients who experienced allograft rejection within the initial 10 days post-transplant was significantly less than in recipients $(n=11)$ who were rejection-free during this interval $(75 \pm 0.3$ vs 82 $\pm 1 \mathrm{SU} / \mathrm{ml} ; P=0.013$ ). A rise in PBCA to well within the normal range was seen during the fourth through sixth days in all patients not experiencing a rejection episode.

Changes in PBCA paralleled, in general, the clinical response to antirejection treatment. A gradual rise in PBCA toward normal was seen in most patients coincident with a salutary response to increased immunosupprcssion. Patients who had a rejection episode associated with low PBCA and who were successfully treated had a PBCA on discharge of $83 \pm 2 \mathrm{SU} / \mathrm{ml}$. In six cases of rejection, PBCA continued to fall for at least 7 days. Further increases in immunosuppressive therapy with continued intravenous steroid pulses or antilymphoblast globulin were required in four of the six to control the rejection episodes. The other two patients had eventual restoration of normal PBCA at 14 and 24 days, respectively, after antirejection therapy. Patients who did not experience a rejection episode and whose $\mathrm{PBCA}$ remained normal during the course of hospitalization had a mean PBCA at discharge of $81 \pm 4$ $\mathrm{SU} / \mathrm{ml}$.

Transplant nephrectomy was performed for severe rejection in six individuals who had low PBCA. In four of these cases, PBCA was less than $50 \mathrm{SU} / \mathrm{ml}$ on two or more occasions. Overall, there were five patients in the study group with PBCA less than 50 $\mathrm{SU} / \mathrm{ml}$ on two or more occasions, of whom four required transplant nephrectomy for uncontrollable rejection.

Nine episodes of cyclosporine nephrotoxicity were encountered in seven patients. A high cyclosporine blood trough level was noted in each case. There were no clinical signs consistent with rejection aside from elevated serum creatinine levels. The sine qua non of nephrotoxicity was a return of serum creatinine levels toward normal following reduction of the cyclosporine dose. In one case, a biopsy further substantiated the diagnosis of nephrotoxicity. Measurements of PBCA during these nine episodes of cyclosporine nephrotoxicity were normal in every case.

\section{DISCUSSION}

Catalase, the first enzyme to be identified, was described by Thernard in 1818 [8]. While the highest concentrations of catalase are in liver, erythrocytes, kidney, heart, muscle, spleen, lung, pancreas, skeletal muscle, and brain, significant catalase activity is also found in white blood cells [8]. The primary function of this ubiquitous enzyme is the metabolism of hydrogen peroxide to water and oxygen $[8,9]$.

In the clinical setting, catalase activity has been determined in urine [14-16], serum [8, 10], erythrocytes [12], and whole blood [17]. In each instance, the method utilized was different, as were the units for expressing enzyme activity. The disk-flotation method for the measurement of catalase activity was proposed by Gagnon and colleagues in 1959 
[13] and has been shown to be a simple, rapid, and accurate assay $[14,15,18]$.

We measured peripheral blood catalase activity (PBCA) in 31 renal transplant recipients and in 10 normal volunteers utilizing the disk-flotation method. PBCA was decreased in $96 \%$ of rejection episodes. Furthermore, very low levels of PBCA (less than $50 \mathrm{SU} / \mathrm{ml}$ on two or more occasions) were indicative of a more severe allograft rejection reaction which required a transplant nephrectomy in four of five individuals. Successful treatment of a rejection episode was associated with a normalization of PBCA. Of those patients with persistently low PBCA following initial antirejection therapy with methylprednisolone, two-thirds required additional steroid pulses and/or antilymphoblast globulin.

Allograft rejection may be precipitated by subtherapeutic levels of cyclosporine. We examined PBCA and cyclosporine blood levels when rejection was diagnosed but found no significant correlation. Of interest were the nine episodes of cyclosporine nephrotoxicity which were identified. On each occasion, the patient presented with a cyclosporine level greater than $250 \mathrm{ng} / \mathrm{ml}$, a rising serum creatinine in the absence of other objective criteria of allograft rejection, and a PBCA that was normal. A decrease in the cyclosporine dosage was associated with a fall in serum creatinine in each case.

The pathogenesis of allograft rejection is incompletely understood. Hayry et al. [3] have described the process of rejection as consisting of four overlapping components: (i) induction of rejection, (ii) the immune response toward the graft, (iii) the inflammatory response and the regulation of inflammation by the immune response, and (iv) the effector mechanisms in situ.

Recently, the cellular nature of the inflammatory infiltrate in the rejecting renal allograft has become the subject of considerable interest. In drug-unmodified rejection, monocytes are detected in a kidney allograft as early as the first day of transplantation [1]. With ongoing rejection, a rapid maturation of blood-borne monocytes into tissue macrophages occurs and progressive destruction of the graft ensues. In severe rejection substantial numbers of polymorphonuclear leukocytes also infiltrate the graft [3]. In this setting, tissue injury may be mediated by the generation of phagocyte-derived oxygen free radicals, the so-called respiratory burst $[1,2]$. Superoxide anion and hydroxyl radicals thereby produced are toxic to biomolecules $[5,6]$ and can lead to cellular injury through lipid peroxidation of mitochrondrial, lysosomal, and plasma membranes [5, 19].

Under normal conditions, tissues contain enough free radical scavengers to protect against oxygen free radical damage. Catalase protects against tissue injury by the inactivation of hydrogen peroxide. Low levels of catalase activity may play a permissive role in ongoing graft rejection. We have been able to determine using mixing studies that the decrease in PBCA is not due to the generation of a blocking factor in the periphery. One possibility may be a decrease in catalase production, although this seems unlikely. Another reason for decreased PBCA may relate to increased enzyme catabolism in the rejecting allograft [7]. It would therefore be of interest to measure catalase in the allograft.

In this study, we have demonstrated that a decrease in PBCA is a sensitive marker of renal allograft rejection. PBCA remains normal during episodes of rising creatinine associated with cyclosporine nephotoxicity, suggesting that PBCA provides a rapid and inexpensive discriminant from allograft rejection. Although the mechanisms accounting for these observations are not understood, reduced catalase activity may implicate oxygen free radicals in the early pathogenesis of renal allograft rejection.

\section{REFERENCES}

1. Babior, B. L., Rosen, R. E., McMurrich, B. J., et al. Arrangement of the respiratory burst oxidase in the plasma membrane of the neutrophil. J. Clin. Invest. 67: 1724, 1981.

2. Schwartz, R. W., Kois, E., Campbell, D. A., et al. Oxygen consumption by peripheral blood mononu- 
clear cells: A predictor of canine renal allograft rejection. Transplant. Proc. 19: 1110, 1987.

3. Hayry, P., von Willebrand, E., Parthenais, E., et al. The inflammatory mechanisms of allograft rejection. Immunol. Rev. 77: 85, 1984.

4. McWhinnie, D. L., Thompson, J. F., Taylor, H. M., et al. Morphometric analysis of cellular infiltration assessed by monoclonal antibody labeling in sequential human renal allograft biopsies. Transplantation 42: 352, 1986.

5. Halliwell, B. Production of superoxide, hydrogen peroxide, and hydroxyl radicals by phagocytic cells: A cause of chronic inflammatory disease. Cell. Biol. Int. Rep. 6: 529, 1982.

6. Fridovich, I. The biology of oxygen radicals. Science 201: 875, 1978 .

7. Kloc, M., Moiler, K., and Stepkowski, S. Superoxide dismutase decrease in cardiac transplants. Transplantation 41: 794, 1986.

8. Meszros, I., Goth, L., and Vattay, G. Y. The value of serum catalase activity determinations in acute pancreatitis. Dig. Dis. 18: 1035, 1973.

9. Roos, D., Weening, R. S., Wyss, J. R., et al. Protection of human neutrophils endogenous catalase. Studies with cells from catalase-deficient individuals. J. Clin. Invest. 65: 1515, 1980.

10. Tsukiyama, Y., Kubota, Y., Misumi, T., Fukuda, $H$., and Nakayama, $M$. Studies on serum catalase in pancreas disorders. Med. J. Osaka Univ. 12: 105, 1961.

11. Yamagata, S., and Seino, S. The blood and plasma catalase content in blood diseases. Tohoku J. Exp. Med. 57: 101, 1952.

12. Chanhan, D. P., Gupta, P. H., Nampoothiri, M. R. N., Singhal, P. C., Chugh, K. S., and Nair, C. R. Determination of erythrocyte superoxide dismutase, catalase, glucosc-6-phosphatc dchydrogenase, reduced glutathine and malonyldialdehyde in uremia. Clin. Chim. Acta 123: 153, 1982.

13. Gagnon, M., Hunting, W. M., and Esselin, B. New method of catalase determination. Anal. Chem. 31: 144, 1959.

14. Charbonneau, R., Therrin, J., and Gagnon, M. Detection and measurement of bacterial catalase by the disk-flotation method using the Catalasemeter ${ }^{R}$. Canad. J. Microbiol. 21: 580, 1974.

15. Braude, A. I., and Berkokitz, H. Detection of urinary catalase by disk-flotation. I. Clin. Invest. 57: 490, 1961.

16. Montgomerie, J. Z., Kalmanson, G. M., and Guze, L. B. The use of the catalase test to detect significant bacteriuria. Amer. J. Med. Sci. 251: 94, 1966.

17. Gross, V. J., Hartwig, A., and Golding, A. Ein verbesserter siebtest zur katalasebestimmung im blut. Z. Med. Labortech. 16: 336, 1975.

18. Moutsos, S. E., Stein, H., and Shapiro, A. P. Evaluation of the urinary catalase test in hypertensive vascular disease. J. Lab. Clin. Med. 59: 847, 1962.

19. Paller, M. S., Hoidal, J. R., and Ferris, T. F. Oxygen free radicals in ischemic acute renal failure in the rat. J. Clin. Invest. 74: 1156, 1984. 